\title{
Dynamic Analysis of a Pyroprocessing Coupled SFR Fuel Recycling
}

\author{
Fanxing Gao and Won Il Ko \\ Division of Nuclear Fuel Cycle Systems Analysis, Korea Atomic Energy Research Institute, Yuseong, \\ Daejeon 305-353, Republic of Korea \\ Correspondence should be addressed to Won Il Ko, nwiko@kaeri.re.kr
}

Received 2 February 2012; Revised 4 April 2012; Accepted 5 April 2012

Academic Editor: Massimo Salvatores

Copyright ( 2012 F. Gao and W. I. Ko. This is an open access article distributed under the Creative Commons Attribution License, which permits unrestricted use, distribution, and reproduction in any medium, provided the original work is properly cited.

\begin{abstract}
Numerous studies have attempted to solve the problems constraining the sustainable utilization of nuclear power, for example, the already accumulated HLWs, the worsening environment due to greenhouse emissions, the questionable reliability of natural uranium resources, and the argument over nuclear safety, which are certainly top issues to be addressed. A well-organized nuclear fuel cycle system is the basis for nuclear power sustainability. Therefore, which type of reactor to be employed and whether or not to adopt a reprocessing technique for spent fuel are two key issues to be addressed. A Sodium Fast Reactor (SFR), a Generation IV reactor, has gained considerable attention worldwide. SFR recycling coupled to pyroprocessing, a so-called Pyro-SFR Recycling, shows promising advantages, and therefore, this paper focuses on exploring a strategy of how to realize it, which can offer informative procedures for a better use of nuclear power. A dynamic model has been developed to quantitatively analyze a countryspecific case employing two scenarios, a once-through and Pyro-SFR, for a comprehensive comparison, especially focusing on the uranium utilization, the HLW reduction, and the electricity generation cost.
\end{abstract}

\section{Introduction}

There are generally two methods used to perform a nuclear fuel cycle system analysis, namely, an equilibrium model and a dynamic model. An equilibrium (or steady-state) model focuses on a batch study built with certain assumptions: the referred reactors and fuel cycle facilities already exist and are in perfect operation regardless of the technological, political, and economic constraints on the reactor and backend process implementation; the derived nuclear fuel cycles are well balanced and organized by different types of reactors with ideal ratios, and the associated infrastructures are already built. However, inevitably these simplified and idealcondition assumptions appear optimistic in that they omit several important preconditions, including technological maturity, the time needed to reach equilibrium states, social and political concerns constraining the deployment of fuelcycle technologies, and the economic competitiveness of the different fuel cycles considered [1-5].

It should be noted that the technology readiness level of each potential option is quite different, for example, the once-through cycling (OT) is currently available, but the components in the sodium fast-reactor-involved recycling require several decades to be fully applicable $[1,2,6]$. When to start building a certain component of the optimal option can be answered using a dynamic model.

In our previous studies, a leading alternative, PyroSFR recycling, has been derived with regard to several key criteria by employing an overall evaluation based on an equilibrium model $[1,2]$. However, the outcome is for a general case, or a theoretical study, which may not be suitable for a specific country due to its own particular situation. Therefore, the goal of the equilibrium model study is to explore a generally optimistic fuel cycle alternative, which may be helpful in understanding the fuel cycle systematically and comprehensively and offer guidance to the promising development. Moreover, the equilibrium model is somewhat too ideal without consideration of several important factors, for example, the timing, technology readiness, and unit cost changes. For a country with specific interests in an objective situation, a variant may be more suitable, and therefore, a country-specific dynamic model has been used 
to explore a relative realistic case following the guidelines of the equilibrium model $[2,3,5]$.

Based on the equilibrium model study, the SFR involved closed fuel cycle options showing explicit advantages, and therefore, a dynamic model was used to analyze Pyro-SFR fuel cycles with consideration of the timing as a means to answer the following questions. (1) When and how to deploy a reactor fleet to meet the future electricity demand? (2) How much uranium will be consumed by 2100? (3) How large is the spent fuel inventory? (4) What is the state of the proliferation-sensitive actinides inventory by the end of $21 \mathrm{st}$ century? (5) Which one is more economically competitive, OT or Pyro-SFR? (6) What is the promising strategy of deploying breakeven reactors (BEs), such as an SFR with a CR of 1.0, and burner reactors (BNs), such as an SFR with a CR of $0.70[7,8]$ ? (7) How do the discount rates affect the generation cost of an OT and Pyro-SFR? A once-through option was selected for a comparison with Pyro-SFR for a comprehensive evaluation.

The dynamic model offers a better way to simulate the deployment process of a fuel cycle, which may take several decades. Based on the direction and final target set by the equilibrium model, it is the role of dynamic model to indicate when and how to realize this.

\section{Calculation Basis and Methodology}

2.1. Reactors and Reprocessing Technology. Generally, two decisions, that is, which kind of reactor to employ and whether or not to deploy a reprocessing technology, mainly determine the direction of the nuclear fuel cycle. The PWR is currently the most popular reactor commercially employed worldwide. Therefore, the parameters of the PWR can refer to the industry facilities. The parameters of SFR, however, mainly come from the conceptual design study with an emphasis on the conversion ratio.

With regard to the specific characteristic of SFR spent fuel, that is, high-burnup and high-plutonium-concentration, the pyroprocessing employing electro-metallurgical techniques in a molten salt medium has the potential to replace the conventional wet reprocessing technology for the treatment of short-cooled SFR spent fuel. The pyroprocessing has been developed to treat the spent oxide fuel discharged from PWRs and recycle the metallic components containing TRUs for SFRs [9, 10]. The metal-fueled SFR using alloys of Actinides-Zirconium (AcZr) has a high potential of recycling actinides by integrating with the pyroprocessing. Accordingly, the pyroprocessing has been assumed to treat metallic SFR spent fuels. However, it should be noted that in this study there are two kinds of spent fuels treated, that is, the spent PWR fuels and the spent fuels of fast reactor. The treatment of PWR spent oxide fuel is for feeding fast reactor with TRU fuels, and the treatment of the spent fuels of fast reactor is for sustaining the Pyro-SFR cycles. According to the different spent fuels to be treated, the locations or organizations of these two pyroprocessing facilities are different. Typically, SFR spent fuel reprocessing is colocated with the fast reactor, and however, LWR spent fuel reprocessing is centralized due to the capacity difference.
In this study, for a country-specific case study, an assumed country that has mastered certain nuclear power operations experience with a PWR spent fuel inventory of $5 \mathrm{ktHM}$ has been adopted. A high population with a small territory and intense dependence of imported uranium are the special characteristics of the assumed country, which makes resource utilization and waste management important. In this study, uranium resource utilization and the amount of waste generation with regard to the fuel cycle options are evaluated in particular, which are indispensable considerations for directing the assumed country toward energy sustainability, as the scarce amount of natural uranium resources and the difficulty of deploying an underground repository for HLW disposal require a longer time, especially due to its high population and small territory.

With regard to the limited domestic uranium resources and issues of HLW disposal, this country plans to transfer the current reactor fleet consisting of PWRs into a combination of advanced PWR and GEN-IV reactors by introducing SFRs and pyroprocessing to close the fuel cycle. Upon consideration of proliferation resistance, two SFR reactors were employed with a conversion ratio no more than 1 , or 0.70 and 1.00. The specifications of the PWR and SFRs are listed in Table 1.

The purpose of this study is to simulate and analyze the assumed country with some nuclear power experience and has an intense interest in developing nuclear power. Therefore, at the beginning it was assumed that the specific country has 5 newly built PWR reactors and a certain amount of accumulated spent fuel inventory for a promising introduction of SFR. Actually, such a case study has a wide scale of application, especially for the nuclear power new comers.

2.2. Nuclear Cycle Specification. In the OT Cycle presented in Figure 1(a). SFs from PWRs would be directly sent to a permanent disposal site without further processing. Therefore, the cycle considers only one type of nuclear reactor, and there is no reprocessing associated with the SF under the OT Cycle concept.

Spent $\mathrm{UO}_{2}$ fuel from a PWR is treated by the pyroprocessing to separate TRU. The recovered TRUs through the process would be recycled into the fast reactors to close the fuel cycle as described in Figure 1(b). The fuel cycle will be referred to as the Pyro-SFR cycle throughout this paper. The same conversion ratios have also been applied to this cycle. Pyroprocessing is suitable for a country that has not been developing a relatively proliferation-risky PUREX but wants to realize a closed fuel cycle, as the pyroprocessing is deemed capable of depositing TRU all together on a liquid $\mathrm{Cd}$ cathode without producing pure $\mathrm{Pu}$ consequently with a high proliferation resistance. The impact of CR on the SFR to PWR core ratio was determined by the consumption of TRU, because with a higher CR less TRU was burned, and thus fewer PWRs were required for TRU production to support SFRs. The electricity produced would be compatibly distributed between the PWR and SFR. The spent fuel compositions and fuel cycle parameters are listed in Table 2. 
TABLE 1: Characteristics of the reference PWR and SFR.

\begin{tabular}{lccc}
\hline Reactor Parameters & PWR & SFR $(\mathrm{CR}=0.71)$ & SFR $(\mathrm{CR}=1.0)$ \\
\hline Electric power (MWe) & 1000 & 600 & 600 \\
Thermal efficiency $(\%)$ & 34.23 & 39.4 & 39.4 \\
Thermal power (MWt) & 2921.40 & $1,522.8$ & $1,522.8$ \\
Load factor & 0.85 & 0.85 & 0.85 \\
Cycle length (full power day) & 290 & 304 & 550 \\
No. of batches & 3 & 5 & 3 \\
\hline
\end{tabular}

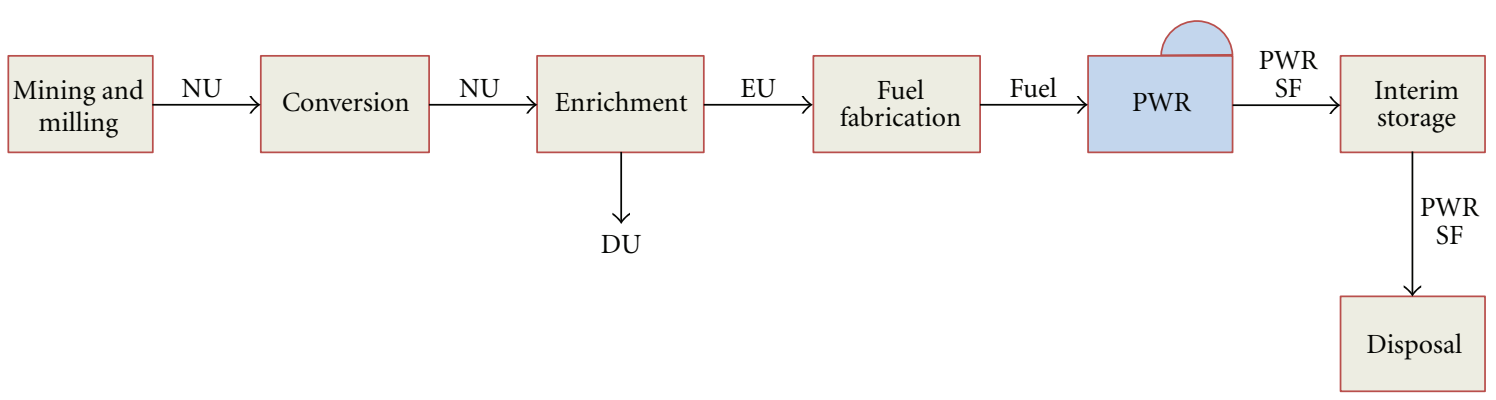

(a) OT

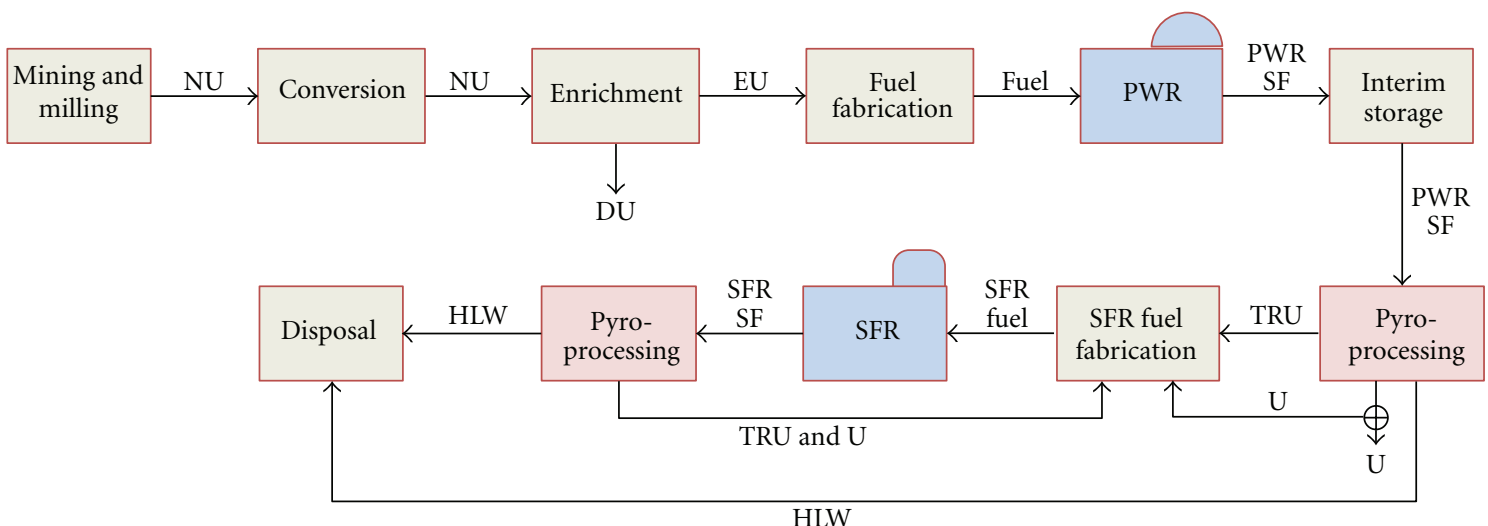

$\begin{array}{ll}\text { NU: natural uranium } & \text { SF: spent fuel } \\ \text { DU: depleted uranium } & \text { TRU: trans uranium } \\ \text { EU: enriched uranium } & \end{array}$

(b) Pyro-SFR

Figure 1: Schematic description of Pyro-SFR fuel cycle option. *NU: natural uranium; DU: depleted uranium; EU: enriched uranium; SF: spent fuel; TRU: trans uranium.

TABLE 2: Parameters of fuel cycle options.

\begin{tabular}{lcc}
\hline Fuel Cycle & OT & Pyro-SFR \\
\hline Enrichment & NU: $0.71 \%{ }^{235} \mathrm{U}$ DU: $0.25 \%{ }^{235} \mathrm{U}$ EU: $4.5 \%{ }^{235} \mathrm{U}$ & NU: $0.71 \%{ }^{235} \mathrm{U}$ DU: $0.25 \%{ }^{235} \mathrm{U}$ EU: $4.5 \%{ }^{235} \mathrm{U}$ \\
PWR fuel Burnup $\left(\mathrm{UO}_{2}\right)$ & $55 \mathrm{GWd} / \mathrm{tHM}$ & $55 \mathrm{GWd} / \mathrm{tHM}$ \\
Back-end for PWR SF & - & Pyroprocessing loss: $0.1 \%$ major waste: FP \\
Metallic TRU SFR fuel $(\mathrm{CR}=0.71)$ & - & Burnup: $131 \mathrm{GWd} / \mathrm{tHM}$ TRU: $30 \%$ \\
Metallic TRU SFR fuel $(\mathrm{CR}=1.00)$ & - & Burnup: $100 \mathrm{GWd} / \mathrm{tHM}$ TRU: $17 \%$ \\
Back end for SFR SF & - & Pyroprocessing loss: $0.1 \%$ major waste: FP \\
\hline
\end{tabular}


TABLE 3: Unit costs for nuclear fuel cycle steps.

\begin{tabular}{|c|c|c|c|c|}
\hline & & & Unit & Unit cost \\
\hline \multirow{3}{*}{ Overnight cost } & PWR & & $\$ / \mathrm{kWe}$ & 4244 \\
\hline & SFR & & $\$ / \mathrm{kWe}$ & 5092 \\
\hline & \multicolumn{2}{|c|}{ O\&M cost charge rate } & & $4.00 \%$ \\
\hline \multirow{14}{*}{ Nuclear fuel cycle } & \multicolumn{2}{|c|}{ Uranium } & $\$ / \mathrm{kgU}$ & 172 \\
\hline & \multicolumn{2}{|c|}{ Conversion } & $\$ / \mathrm{kgU}$ & 12 \\
\hline & \multicolumn{2}{|c|}{ Enrichment } & \$/SWU & 155 \\
\hline & Fabrication & $\mathrm{UO}_{2}$ fuel & $\$ / \mathrm{kgHM}$ & 269 \\
\hline & Reprocessing & PWR SF pyro. & $\$ / \mathrm{kgHM}$ & 1194 \\
\hline & Pyro. and fab. & Pyro. and SFR metal fuel fab. & $\$ / \mathrm{kgHM}$ & 5599 \\
\hline & \multirow{3}{*}{ Long-term stro. } & Depleted U & $\$ / \mathrm{kgHM}$ & 5 \\
\hline & & Reprocessed U & $\$ / \mathrm{kgHM}$ & 3 \\
\hline & & $\mathrm{SF}_{-} \mathrm{UO}_{2}$ & $\$ / \mathrm{kgHM}$ & 156 \\
\hline & \multirow[t]{2}{*}{ Tran. and sto. } & Decay storage & $\$ / \mathrm{kgIHM}$ & 17473 \\
\hline & & HLW & $\$ / \mathrm{m}^{3}$ & 114698 \\
\hline & \multirow{2}{*}{ Packaging } & $\mathrm{SF}_{-} \mathrm{UO}_{2}$ & $\$ / \mathrm{kgHM}$ & 35 \\
\hline & & HLW from pyro. & $\$ / \mathrm{m}^{3}$ & 35485 \\
\hline & \multicolumn{2}{|c|}{ Underground cost } & $\$ / \mathrm{m}^{3}$ & 213 \\
\hline & \multicolumn{3}{|c|}{ Decommissioning charge rate } & $15.00 \%$ \\
\hline
\end{tabular}

${ }^{*}$ SWU stands for separative work unit.

2.3. Unit Cost Specification. The main sources of the unit cost data used in this study were mainly from the OECD/NEA study [11-13] and Advanced Fuel Cycle Cost Basis (short for AFCCB) [14-16], and engineering judgments were used when certain data were not available. The input cost data are listed in Table 3. All the data are presented in 2010 dollars. For the data not in 2010 values, an escalation rate of $3 \%$ was used to realize the conversion of the base year. Some specifications of the key components are described as follows.

The cost uncertainties concerning pyroprocessing and capital cost of SFR are unavoidable according to the R\&D status. There are numerous studies in the capital costs and pyroporcessing cost, but it is difficult to determine an exact or accurate data and the uncertainties are obvious. In this study, we focus on the impacts of inflation ratio and uranium price prediction model (escalation ratio), and therefore, the somewhat reliable unit costs from OECD studies and AFCCB have been adopted.

In this paper, the pyroprocessing cost was calculated by multiplying the material flow and the corresponding unit costs. The unit cost was obtained by literature survey and reviewed by expert term of Korea Atomic Energy Research and discounted accordingly to the initial year. Therefore, there is no information concerning the capacities of several facilities. However, the authors do admit the importance of facility capacity in the deployment of a nuclear fuel cycle system.

2.4. Calculations. An excel code was composed to finish the material flow study. The equations used to calculate the fuels and services needed to meet the energy demand are the same with those used in the equilibrium model $[17,18]$. In the cost analysis, the levelized fuel cycle costs (LFCCs) and

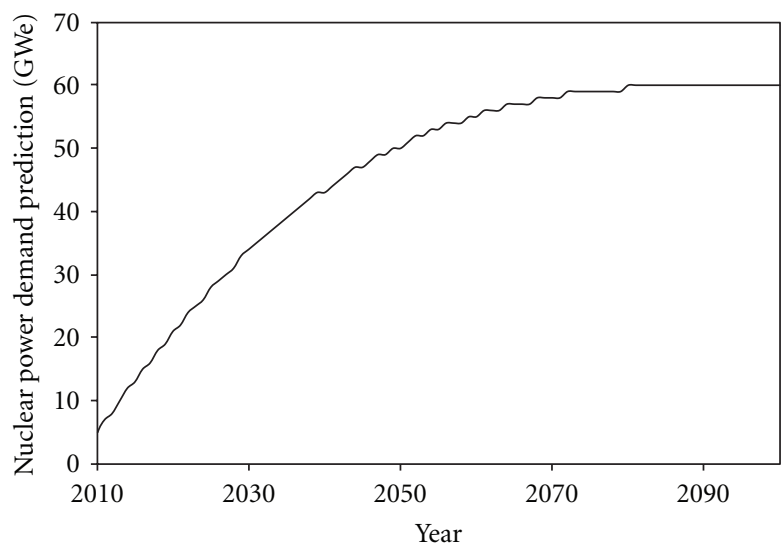

FIgURE 2: Electricity demand prediction.

levelized generation cost (LGC) have been derived in terms of mills/kWh, respectively, for a fair comparison among the different FCCs. the LFCC and LGC (consisting of all reactors and the supporting fuel cycle services) calculation methods can be referred from the following papers: $[3,17,18]$.

2.5. Electricity Demand Prediction. The energy demand determines the reactor employed and finally affects the material flow. The material flow is the basis for the dynamic model analysis. In this study, the evaluated country has been assumed to pursue a nuclear development plan as follows: the nuclear capacity may reach 35 GWe in 2030, 50 GWe in 2050, and finally $60 \mathrm{GWe}$, and the nuclear power demand prediction is shown in Figure 2 which applies to all the scenarios considered in this study. 


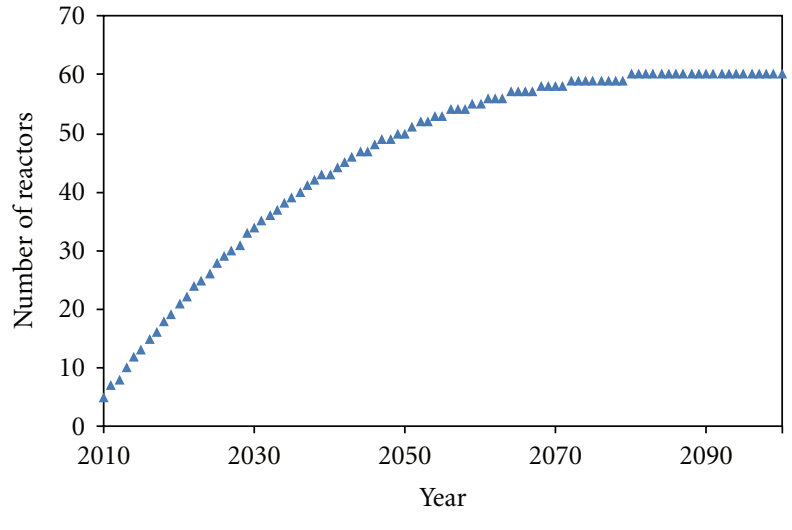

$\triangle$ PWR

FIgURE 3: The reactor fleet of OT.

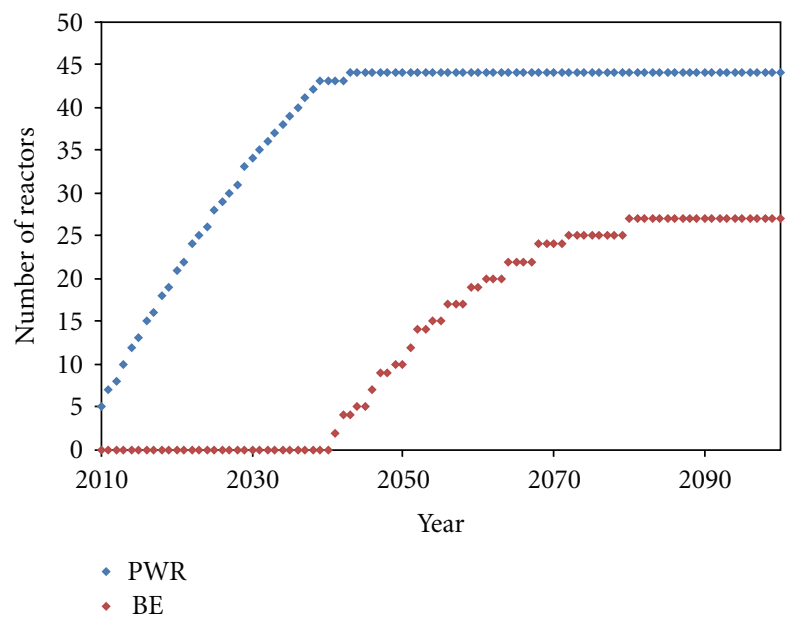

FIgURE 4: The reactor fleet of BN-only case.

2.6. Reactor Fleet Deployment Specification. For the OT option, there is only one type of reactor, or PWR, and thus the capacity of PWRs employed equals the nuclear power demand, as shown in Figure 3. For the Pyro-SFR option, there are three types of reactors considered, that is, PWR, BN, and $\mathrm{BE}$, and thus the reactor fleet deployment strategies are different. Assuming that SFRs will be in operation until 2041, three cases of reactor deployment, that is, BN only, BE only, and $\mathrm{BN} \& \mathrm{BE}$, are specified in Figures 4 and 5, respectively.

A burner (BN) just consumes TRU and a break-even reactor (BE) burns the same amount of TRU as it generates. The reason to employ a $\mathrm{BN}$ mixed with $\mathrm{BE}$ scenario ( $\mathrm{BN}$ \& $\mathrm{BE}$ case) is for a comprehensive comparison to explore the difference performances between the $\mathrm{BN} \& \mathrm{BE}$ mixed case and a sole $\mathrm{BN}$ or $\mathrm{BE}$ case. The principle or the rule of managing the ratio of $\mathrm{BN}$ to $\mathrm{BE}$ in the $\mathrm{BN} \& \mathrm{BE}$ mixed case is shown in Figure 6, which was derived on consideration of several factors, for example, the TRU inventory fueling the fast reactors, the pyroprocessing capacity, the technical readiness, and the experts evaluation. It may not be a fully proved plan. However, it serves well as a useful reference. In this study, it should be noted that because the reactor deployment, the schedule of which depends on

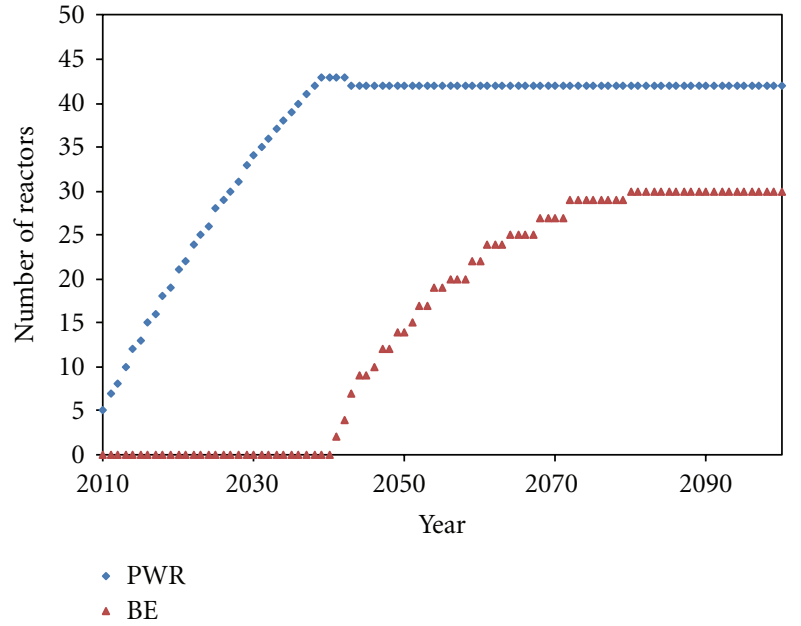

FIgURE 5: The reactor fleet of BE-only case.

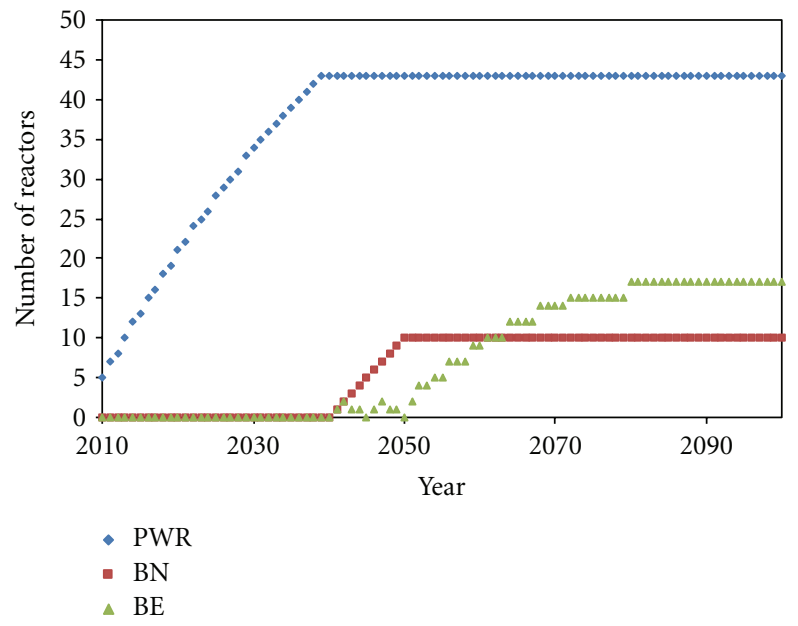

FIgURE 6: The reactor fleet of BN \& BE case.

several factors, plays an important role in controlling the fuel consumption, the waste generation, and the cost, in our future study a more detailed study on the strategy of deployment of new reactors will be carried out.

Some contingency can cause major changes in outcomes, for example, the reactor fleet deployment with consideration of time consumed for the delay of construction or licensing. In this paper, a dynamic model was used to perform a case study with a specific assumption, that is, the deployment of the reactor fleet set in advance will follow the schedule and any disturbs which may probably delay the deployment can be avoided properly. The seemingly easy deployment of a new reactor is based on the assumption that all the constraints during the deployment can be solved timely. In other words, no matter what kind of difficulties may constrain the deployment of a reactor, it can be closed and the deployment will not be affected. This assumption will not affect the dynamic characteristics of the study especially concerning the materials flows, however, which may cause the reduction of some contingency costs. 


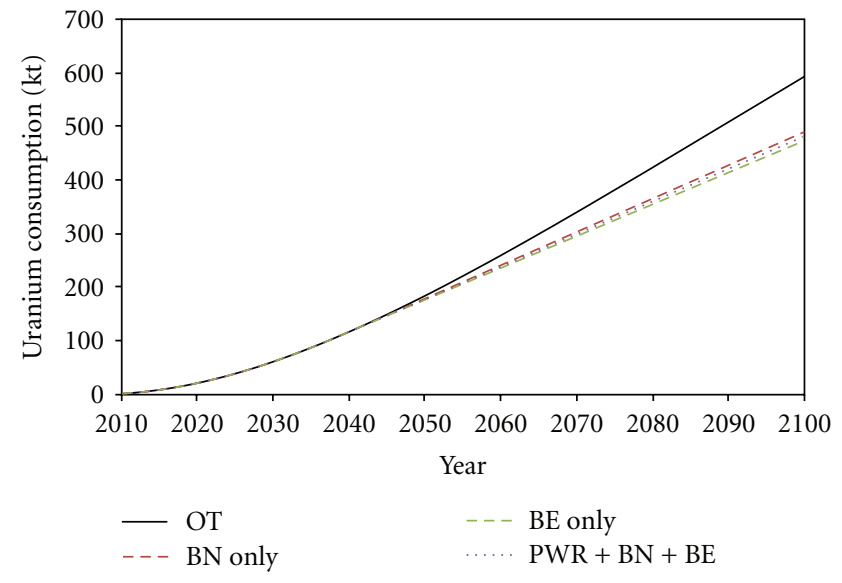

FIGURE 7: Uranium consumption.

2.7. Pyroprocessing Capacity Specification. The reprocessing is the core issue of the back end of a fuel cycle. The impact of pyroprocessing on the fleet of $\mathrm{BN} / \mathrm{BE}$ and the inventory of spent PWR fuel are essential. Generally, there are two strategies concerning the capacity of pyroprocessing facilities, that is, (1) the annual capacity of the facility is determined by a predetermined pattern, which should be verified by the spent fuel inventory and the experts evaluation; (2) the annual capacity is determined by the practical need of the $\mathrm{BN}$ and $\mathrm{BE}$. In this study, the strategy of the capacity pyroprocessing facility follows the TRU needed for refueling the fast reactors, which may be not realistically correct from industrial operation point of view but it is somewhat a clear strategy.

2.8. Consumptions Specification. Dynamic system analysis of nuclear fuel cycle serves as a useful tool for recommending a promising nuclear fuel cycle. Integrated with the outcome of an equilibrium model, it is informative to simulate practical scenario employing a dynamic model. As stated in Section 1, a dynamic mode is deemed to be capable of answering several essential questions concerning the future deployment of nuclear fuel cycle. However, it should be noted that each conclusion derived was based on several assumptions, or the background of the scenario. A slight change to the assumptions can lead to different outcomes. In this study, we mainly focus on a country with an intense interest in nuclear power and an ambitions nuclear power plan. This scenario maybe somewhat too specific, however, which does not affect it to be an informative and useful reference for decision makers.

\section{Results and Discussion}

\subsection{Material Flow Study}

3.1.1. Uranium Consumption. With the reactor fleet pattern deployed as shown in Figure 7, Pyro-SFR options saved around $20 \%$ of uranium due to the bigger burnup derived by the SFRs making use of TRU recovered from PWR spent

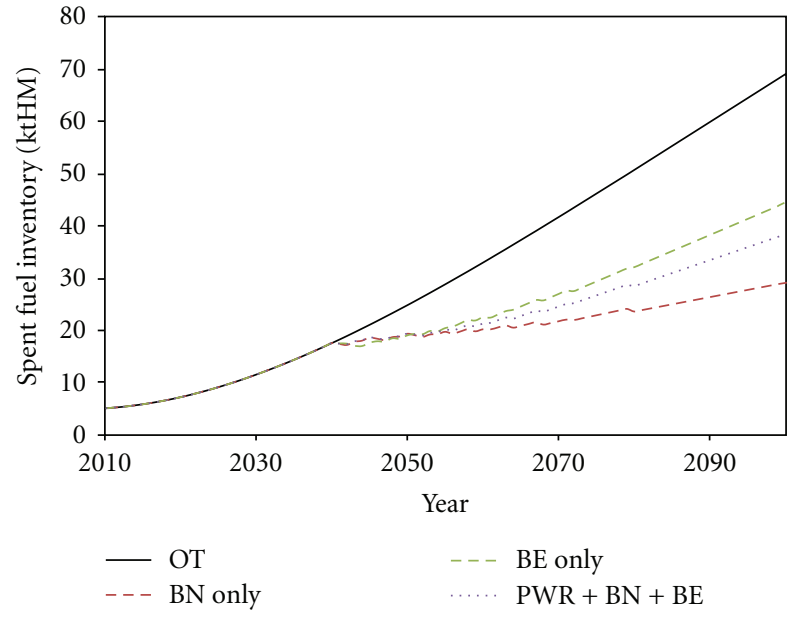

Figure 8: Spent fuel inventory.

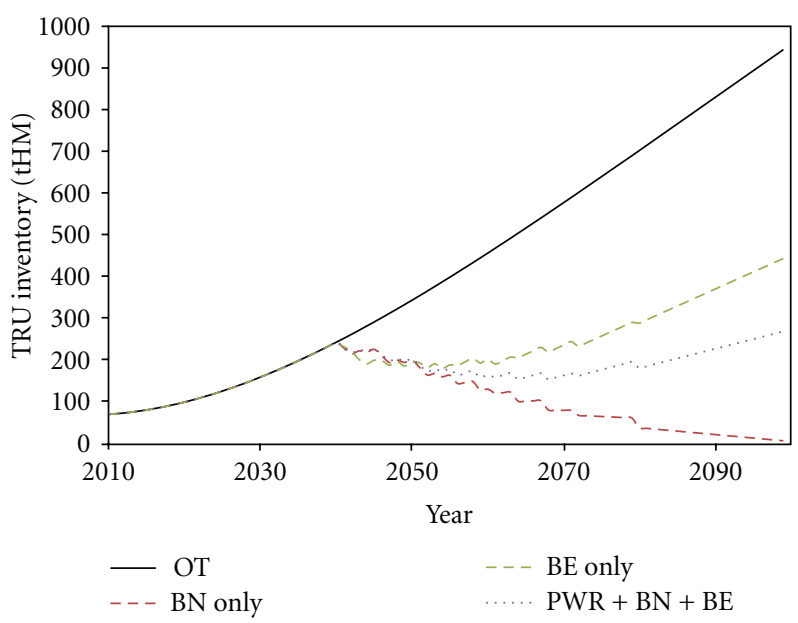

FIgURE 9: TRU inventory.

fuel. Because natural uranium is mainly consumed by PWRs, there is almost no uranium consumption difference between $\mathrm{BN}$-only, BE-only, and PWR $+\mathrm{BN}+\mathrm{BE}$ scenarios.

3.1.2. SF Inventory. Figure 8 shows the spent fuel inventory of these four scenarios. The OT generates the most spent fuel without deploying any spent fuel treatment. Accordingly, with reprocessing, SFR-involved fuel cycles considerably decrease the spent fuel inventory.

3.1.3. Actinide Inventory. Pu once disposed of in a geological repository may become "plutonium mines" and cause a nonproliferation burden. Therefore, out-pile $\mathrm{Pu}$, TRU, and MA inventories were obtained as shown in Figures 9, 10, and 11 , respectively. A BN can consume $18.8 \%$ of the TRU loaded into the reactor, and a BE can consume $1.5 \%$ of the loaded TRU, which explains why the BN-only case generates the smallest amount of Pu. The OT option without reprocessing of PWR spent fuel leaves all spent fuel and therefore generates the largest plutonium mines. In the 


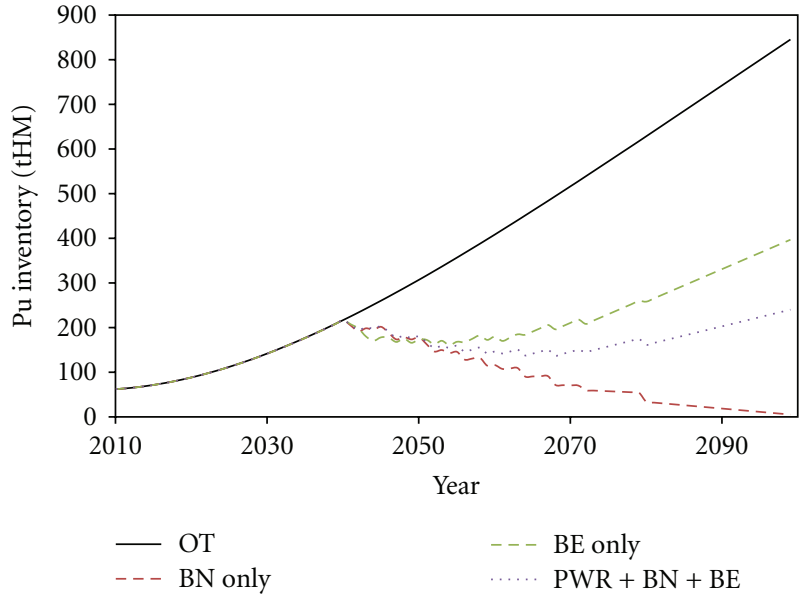

Figure 10: Pu inventory.

BN-only case, almost all of the spent fuel from the PWR was reprocessed with the assumption that there is $5 \mathrm{ktHM}$ of accumulated spent fuel in 2010. However, it should be considered that the deployment of $\mathrm{BN}$ might be constrained due to a lack of TRU to feed the BN, which can be solved by postponing the $\mathrm{BN}$ or reducing the $\mathrm{BN}$ percentage in a reactor fleet.

\subsection{Cost Analysis}

3.2.1. LFCC and LGC. For a fair comparison, the LFCC and LGC of OT and Pyro-SFR (BN \& BE) were calculated, and the detailed cost components are listed in Table 4, based on the same unit costs input into the equilibrium model. In the LFCC costs, for both options, the uranium cost plays a dominant role, $73.4 \%$ for OT and $68.08 \%$ for Pyro-SFR.

For Pyro-SFR case the HLW waste-related costs consists of three parts, that is, the transport and storage cost, the packaging cost, and the disposal underground cost. As listed in Table 4, Pyro-SFR shows obvious advantages over OT concerning the costs of HLW treatments. The disposal of HLW is a burden for nuclear power industry not only because of the troublesome procedures but also because of the high cost, and therefore, it is of great importance to focus on the reduction of HLW. SFR-involved cycle shows clear advantage in reducing the HLW generation, which definitely will contribute to the cost reduction.

On consideration of the relatively smaller share of LFCC in LGC, however, the uranium cost is negligible. In the LGC costs, investment cost and O\&M costs take a considerable share. Therefore, due to the bigger capital cost and O\&M of a SFR, the fewer the SFRs introduced into a reactor fleet, the less expensive the LGC becomes. However, with consideration of the advantage of SFR in reducing the environmental burden and high costs caused by HLW treatments and its contribution in strengthening the uranium resource reliability, it is worth pondering the cost value.

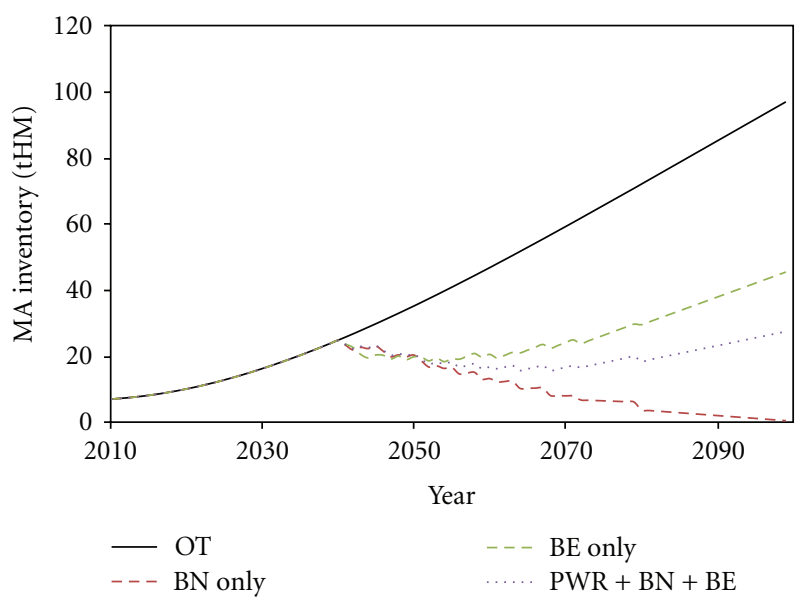

FIGURE 11: MA inventory.

\subsubsection{Sensitivity Analysis}

(1) Escalation Rate. Natural uranium spot price is mainly determined by a balance of supply and demand, which is hard to predict with regard to the considerable amount of the world's nuclear power development and the somewhat unclear uranium resource exploration. In this paper, a simplified uranium price model, an escalation model, which is capable of covering a large promising trend, was used [14-16]. The following equation was employed to obtain the uranium price (net present value) prediction shown in Figure 12:

$$
\mathrm{U}(t)=\frac{\mathrm{U}(0) \times(1+e)^{\left(t-t_{0}\right)}}{(1+r)^{\left(t-t_{0}\right)}},
$$

where $\mathrm{U}(t)$ is the uranium price at time $t(\$ / \mathrm{kgU}), \mathrm{U}(0)$ is the uranium price at the reference date $(\$ / \mathrm{kgU}), e$ stands for the escalation rate, $r$ is the discount rate (e.g., $5 \%$ ), and $t_{0}$ is the reference time.

By changing the escalation rate applied to the uranium price model, the LGC dependent on the escalation rate was obtained and is shown in Figure 13. There is a cross point when the escalation rate surpasses $4.6 \%$, which indicates that when the future uranium price shows the trend indicated by the plot in Figure 13, Pyro-SFR is more competitive than OT by a discount rate of $5 \%$. This indicates that if the uranium price remains as high as $171 \$ / \mathrm{kg}$, with a discount rate of $5 \%$ and an escalation rate of $4.6 \%$, the OT is costly.

(2) Discount Rate. With regard to the lead and lad time of the money distribution pattern, a discount rate (DC) plays a considerable role in affecting the LGC. There are mainly two kinds of discount rates, that is, nominal discount rate and real discount rate. The nominal discount rate covers compensation for money purchase power reduction caused by inflation; a real return; compensation for the extent of risk undertaken by committing capital to this investment. The real discount rate does not consider the inflation. Discount rates have a close relationship with risks involved 
TABLE 4: Levelized cost components (unit: mills/kWh).

\begin{tabular}{|c|c|c|c|c|c|}
\hline & \multirow[t]{2}{*}{ Component } & \multicolumn{2}{|c|}{ OT } & \multicolumn{2}{|c|}{ Pyro-SFR } \\
\hline & & Cost & Share & Cost & Share \\
\hline & Capital cost & 35.05 & $49.49 \%$ & 36.60 & $50.13 \%$ \\
\hline & O\&M & 22.80 & $32.19 \%$ & 24.31 & $33.30 \%$ \\
\hline \multirow{15}{*}{ LFCC } & Uranium & 9.32 & $73.40 \%$ & 8.06 & $68.08 \%$ \\
\hline & Conversion & 0.23 & $1.80 \%$ & 0.21 & $1.80 \%$ \\
\hline & Enrichment & 2.19 & $17.28 \%$ & 2.05 & $17.29 \%$ \\
\hline & PWR fuel fabrication & 0.55 & $4.36 \%$ & 0.52 & $4.36 \%$ \\
\hline & SFR fuel fabrication & - & - & 0.33 & $2.79 \%$ \\
\hline & Subtotal for front-end & 12.29 & $96.84 \%$ & 11.17 & $94.32 \%$ \\
\hline & Transport and dry storage & 0.32 & $2.53 \%$ & 0.13 & $1.14 \%$ \\
\hline & Pyroprocessing & - & - & 0.50 & $4.21 \%$ \\
\hline & Decay storage (Cs/Sr) & - & - & 0.04 & $0.33 \%$ \\
\hline & Packaging cost & 0.07 & $0.57 \%$ & 0.00 & $0.00 \%$ \\
\hline & Disposal underground cost & 0.01 & $0.07 \%$ & 0.00 & $0.00 \%$ \\
\hline & Subtotal for back end & 0.40 & $3.16 \%$ & 0.67 & $5.68 \%$ \\
\hline & LFCC total & 12.69 & $100.00 \%$ & 11.84 & $100.00 \%$ \\
\hline & $\mathrm{D} \& \mathrm{D}$ & 0.28 & $0.40 \%$ & 0.26 & $0.36 \%$ \\
\hline & LGC total & 70.82 & $100.00 \%$ & 73.02 & $100.00 \%$ \\
\hline
\end{tabular}

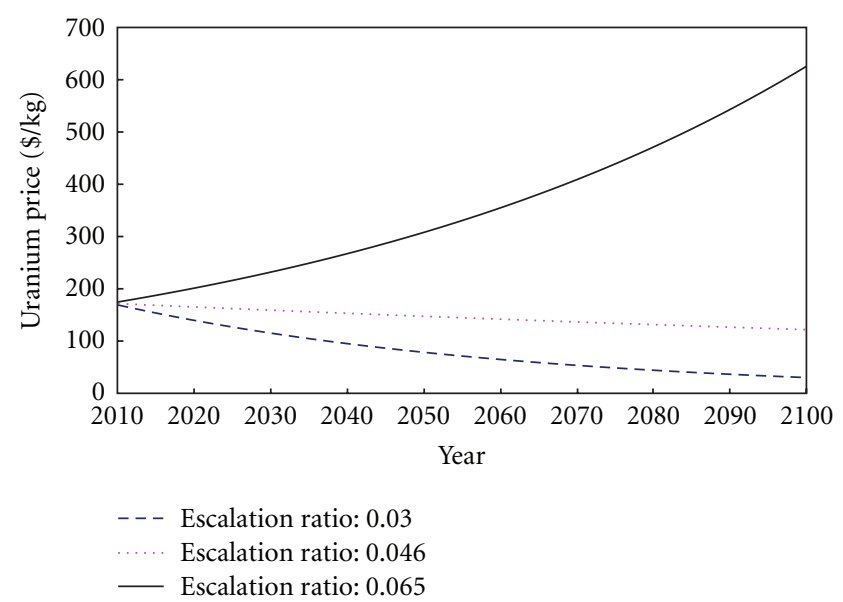

FIgURE 12: Uranium price model with a discount rate of $5 \%$ applied.

in each technique. In the fuel cycle system analysis, various technologies are employed, so case-dependent discount rates should be adopted correspondingly, which leads to different discount rate for each new technology. For projects employing risky technologies, the appropriate discount rate should be somewhat higher than that for a project with less risky technologies. For a fair comparison, it is worth considering the varieties of discount rate. The risks of investing in different components of an NFC and among various NFCs are quite different, it is reasonable not to adopt the same discount rate for all fuel cycle alternatives, and therefrom, a range of real discount rate was applied to each nuclear fuel cycle.

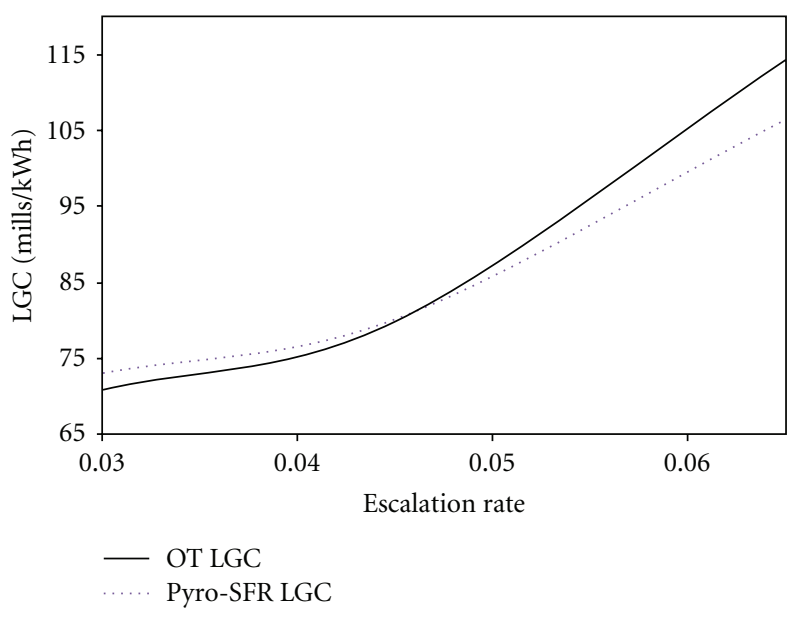

FIGURE 13: LGC dependent on escalation rate.

Consequently, in order to resemble the uncertainty of discount rate, attention was always paid to cover a range of discount rate usually from 0 to $15 \%$ for each fuel cycle option, respectively. Actually, in the same nuclear fuel cycle, however, the big effects due to employing different discount rates for each component should be also taken into account, especially for $\mathrm{D} \& \mathrm{D}$ cost due to its expenditure pattern. Fundamentally, the longer time considered the more important role the discount rate plays. The cost of D\&D is therefore transformed into a neglected value with somewhat $5 \%$ discount rate, however, which might not be the case actually [19]. The contribution of D\&D cost to the LGC will be reconsidered by employing a specified discounting pattern with consideration of the social responsibility. 


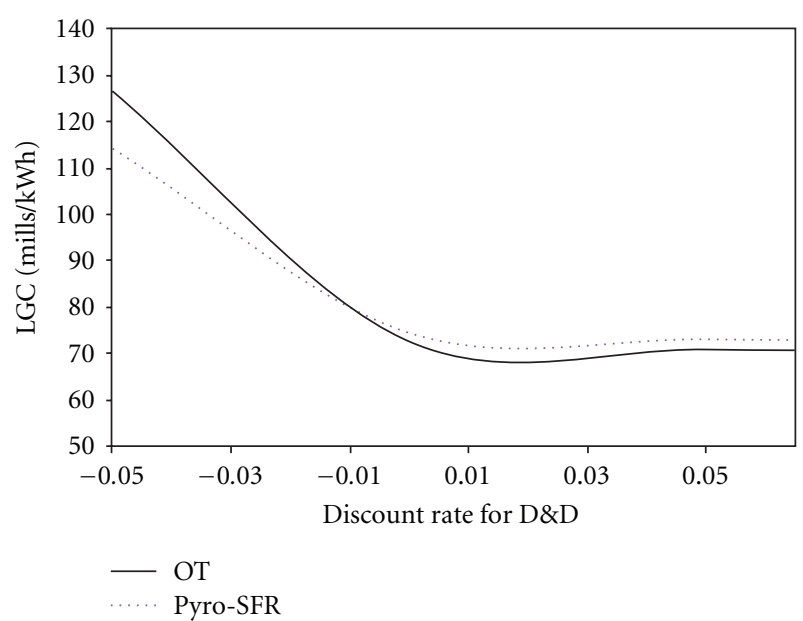

Figure 14: LGC dependent on discount rate for D\&D.

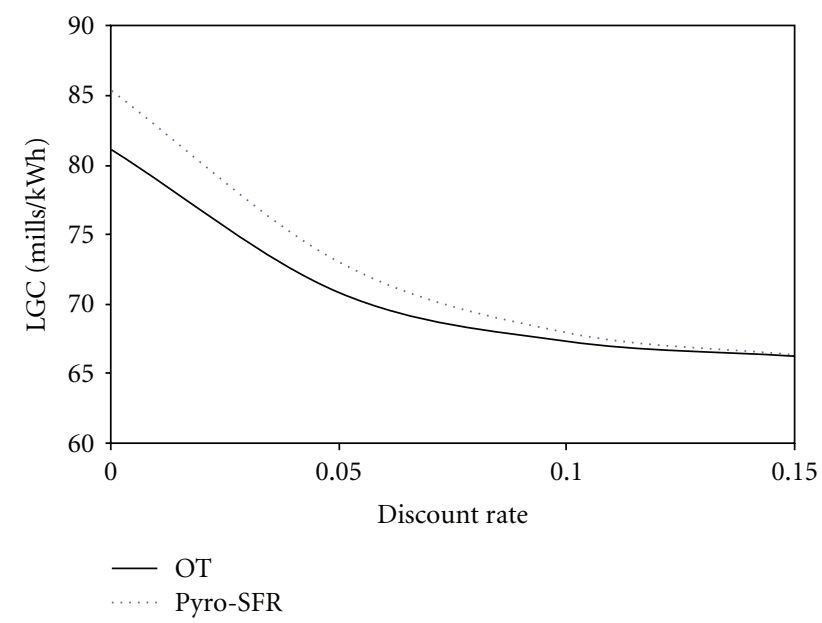

FIGURE 15: LGC dependent on discount rate.

(a) Discount Rate for $D \& D$. Concerning the social pressure and future uncertainty, it was suggested that a specific discount rate should be applied to the decommissioning. To clarify the important impacts of discount rates on LGC, a sensitivity analysis of the discount rate for $\mathrm{D} \& \mathrm{D}$ was carried out, as shown in Figure 14. There is a cross point when the specific discount rate for $\mathrm{D} \& \mathrm{D}$ reaches $-1 \%$. This indicates that, if the social pressure or future uncertainty increases the D\&D cost, the electricity generated by the Pyro-SFR may become cheaper than the OT.

(b) Discount Rate for Fuel Cycles. A sensitivity analysis was also performed for a discount rate applied to all components in the OT and Pyro-SFR. It is explicit that, by increasing the discount rate used, the LGCs of both OT and PyroSFR decrease dramatically, as shown in Figure 15. Therefore, attention should be paid to discount selection, which may affect the outcome considerably, however, without changing the rankings.
It should be noted that the specific discount rate or price escalation rate that represent a value point at which the SFR is as economic as the LWR has been obtained employing a set of unit costs. However, there are unavoidably high uncertainties associated with certain component unit costs, and therefore, by changing the inputted unit costs, the obtained discount rate or escalation rate can be considerably different. In this study, the input unit cost data are from somewhat reliable OECD series studies and AFCCI reports; nevertheless, the unavoidable uncertainties still exist.

\section{Conclusion}

Following the guidance of an equilibrium model study, PyroSFR Recycling was selected to perform a country-specific dynamic analysis by a comparison with OT Cycling to explore a realistic strategy for nuclear fuel cycle deployment in the long term by 2100 .

The reactor fleet deployment in the long term is generally constrained by several factors, that is, a national energy demand, resource sustainability, technology availability, social acceptance, and so forth. Assuming a country has committed an explicit nuclear power development plan with its specific situations concerning resource, technology, and social acceptance, this dynamic study performed a comparison between OT and Pyro-SFR options focusing on the material flow and cost analysis.

Total uranium consumption by the year 2100 can be reduced by burning TRU recovered from spent fuel in SFR, BN, or BE, and therefore, Pyro-SFR options show predominant advantages over the OT option in terms of fuel efficiency. The spent fuel inventory of Pyro-SFR by employing reprocessing is also much smaller than that of OT without any spent fuel treatment. In a Pyro-SFR option, two SFRs with different $\mathrm{CRs}$ were employed (i.e., BN, BE). The TRU metallic fuel for SFR is from the reprocessing of PWR spent fuel, and thus accumulated PWR spent fuel constrains the beginning year of SFR operation and the number of SFRs available. With regard to inventories of a proliferationsensitive material, that is, $\mathrm{Pu}$, TRU, and MA, Pyro-SFR also indicates an advantage over the OT option.

The cost analysis of OT and Pyro-SFR was performed for a comprehensive comparison. LFCC and LGC of an OT and Pyro-SFR were obtained, that is, $12.69 \mathrm{mills} / \mathrm{kWh}$ for LFCC of the OT, 11.84 mills/kWh for LFCC of the Pyro-SFR, $70.82 \mathrm{mills} / \mathrm{kWh}$ for LGC of the OT, and $73.02 \mathrm{mills} / \mathrm{kWh}$. With consideration of the uncertainties of three key parameters which play a considerable role in the cost analysis (i.e., escalation rate applied to the uranium price model, specific discount rate for decommissioning, and discount rate for the whole nuclear fuel cycle), a sensitivity analysis was carried out to compare the LGCs of the two options. If the escalation rate is more than $4.6 \%$, the Pyro-SFR is more economically competitive than the OT. If the future burden of $\mathrm{D} \& \mathrm{D}$ increases considerably, with a specific discount rate of $-1 \%$ applied to $\mathrm{D} \& \mathrm{D}$, the OT is more costly than the PyroSFR. The outcome of a sensitivity analysis of the discount rate applied to the whole fuel cycle indicates that the impact of the discount rate was explicit, and thus more attention should be 
paid to the appropriate selection of a discount rate for the long-term strategy study.

It should be noted that, although this is a countryspecific case study concerning an assumed country with some nuclear experience and an ambitious nuclear plan, both the methods and outcomes of this paper can provide guidance for other future studies.

\section{Acknowledgment}

This work has been carried out under the Nuclear Research and Development Program of Korea Ministry of Education, Science and Technology.

\section{References}

[1] B. H. Park, F. Gao, E. H. Kwon, and W. I. Ko, "Comparative study of different nuclear fuel cycle options: quantitative analysis on material flow," Energy Policy, vol. 39, no. 11, pp. 6916-6924, 2011.

[2] G. Fanxing, Modeling and system analysis of different fuel cycles for nuclear power sustainability, Ph.D. thesis, Department of Quantum Energy and Chemical Engineering, Korea Atomic Energy Research Institute Campus, Korea University of Science \& Technology, Seoul, Republic of Korea, 2012.

[3] DANESS v1.0 Users Manual, Argonne National Laboratory Nuclear Engineering Division, 2004.

[4] B. Dixon, S. Kim, D. Shropshire, S. Piet, G. Matthern, and B. Halsey, "Dynamic systems analysis report for nuclear fuel recycle," Tech. Rep. INL/EXT-08-15201 Rev.1, 2008.

[5] W. I. Ko, Model development for quantitative evaluation of nuclear fuel cycle alternatives and its application, Ph.D. thesis, Department of Nuclear Engineering, KAIST, Daejeon, Republic of Korea, 2000.

[6] W. I. Ko, H. D. Kim, and M. S. Yang, "Advantages of irradiated DUPIC fuels from the perspective of environmental impact," Nuclear Technology, vol. 138, no. 2, pp. 123-139, 2002.

[7] Y. Ishiwatari, Y. Oka, and S. Koshizuka, "Breeding ratio analysis of a fast reactor cooled by supercritical light water," Journal of Nuclear Science and Technology, vol. 38, no. 9, pp. 703-710, 2001.

[8] S. G. Hong, Y. Kim, and F. Venneri, “600 MWe sodium cooled fast reactor core designs for efficient TRU transmutation," in Proceedings of the The Korean Nuclear Society Spring Meeting, Chuncheon, Republic of Korea, May 2006.

[9] M. Cometto, P. Wydler, and R. Chawla, "A comparative physics study of alternative long-term strategies for closure of the nuclear fuel cycle," Annals of Nuclear Energy, vol. 31, no. 4, pp. 413-429, 2004.

[10] T. Inoue, "Actinide recycling by pyro-process with metal fuel FBR for future nuclear fuel cycle system," Progress in Nuclear Energy, vol. 40, no. 3-4, pp. 547-554, 2002.

[11] OECD/NEA, Uranium 2009: Resources, Production and Demand, OECD Nuclear Energy Agency, Paris, France, 2009.

[12] OECD/NEA, The Economics of the Nuclear Fuel Cycle, OECD Nuclear Energy Agency, Paris, France, 1994.

[13] OECD/NEA, "Advanced nuclear fuel cycles and radioactive waste management," Tech. Rep. 5990.OECD, Nuclear Energy Agency (NEA), Paris, France, 2006.

[14] D. Shropshire, K. A. Williams, W. B. Boore et al., "Advanced fuel cycle cost basis,” Tech. Rep. INL/EXT-07-12107, 2007.
[15] D. Shropshire, K. A. Williams, W. B. Boore et al., "Advanced fuel cycle cost basis," Tech. Rep. INL/EXT-07-12107 Rev.1, 2008.

[16] D. Shropshire, K. A. Williams, W. B. Boore et al., "Advanced fuel cycle cost basis," Tech. Rep. INL/EXT-07-12107 Rev.2, 2009.

[17] J. Deutch and E. Moniz, The Future of Nuclear Power: An Interdisciplinary MIT Study, Massachusetts Institute of Technology, Cambridge, Mass, USA, 2003.

[18] M. Bunn, B. van der Zwaan, J. P. Holdren, and S. Fetter, "The economics of reprocessing vs. direct disposal of spent nuclear fuel," Tech. Rep. DE-FG-26-99FT4028, 2003.

[19] H. Khatib, "Review of OECD study into 'Projected costs of generating electricity-2010 Edition,” Energy Policy, vol. 38, no. 10, pp. 5403-5408, 2010. 

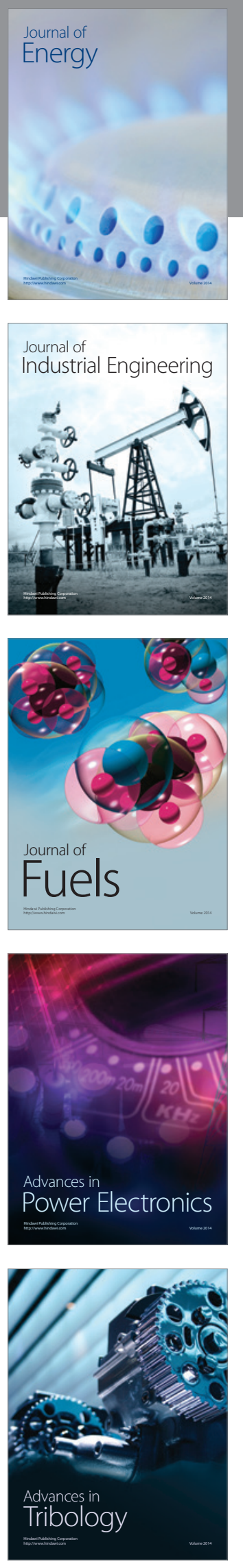
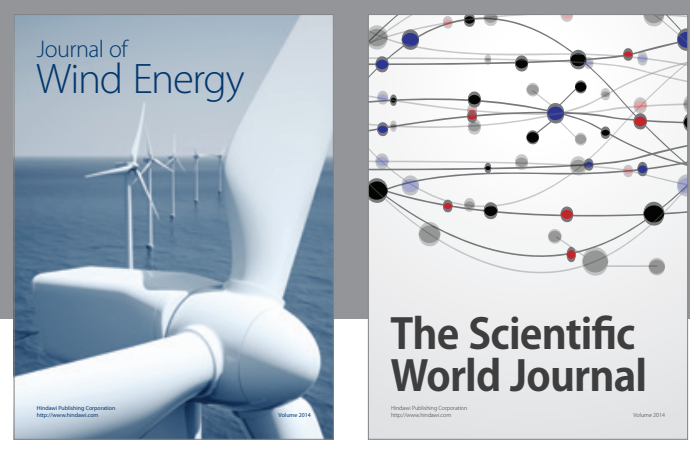

The Scientific World Journal

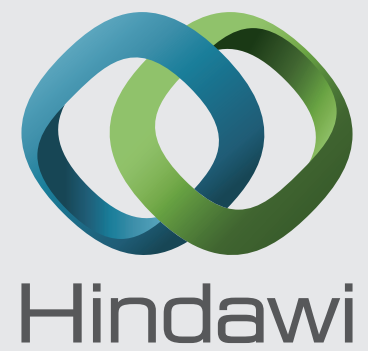

Submit your manuscripts at http://www.hindawi.com
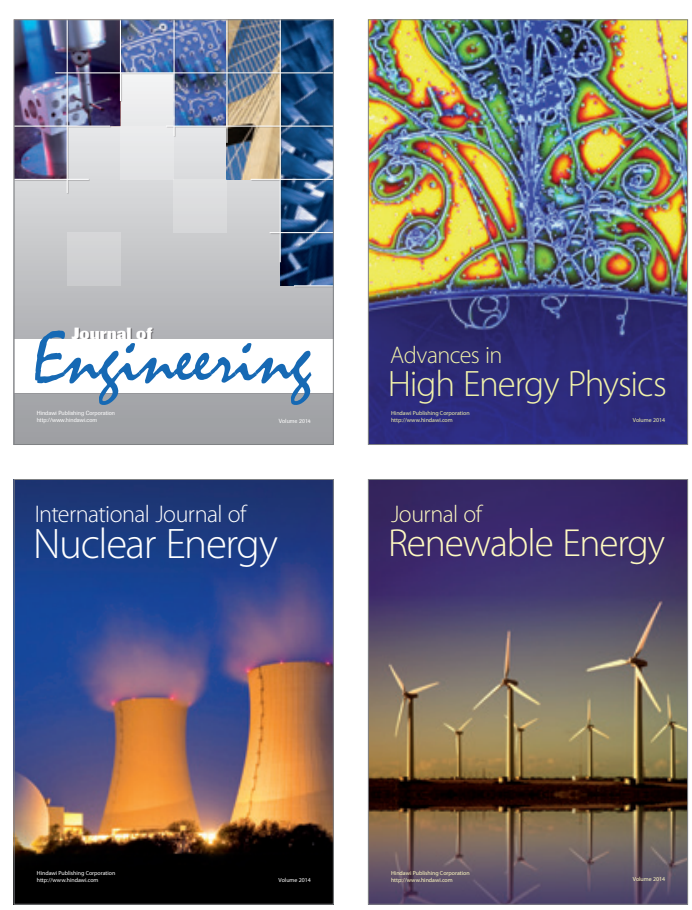

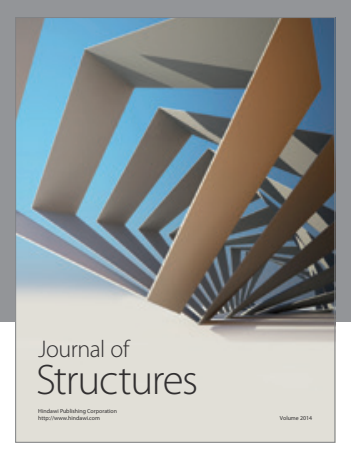

Rotating
Mechinery
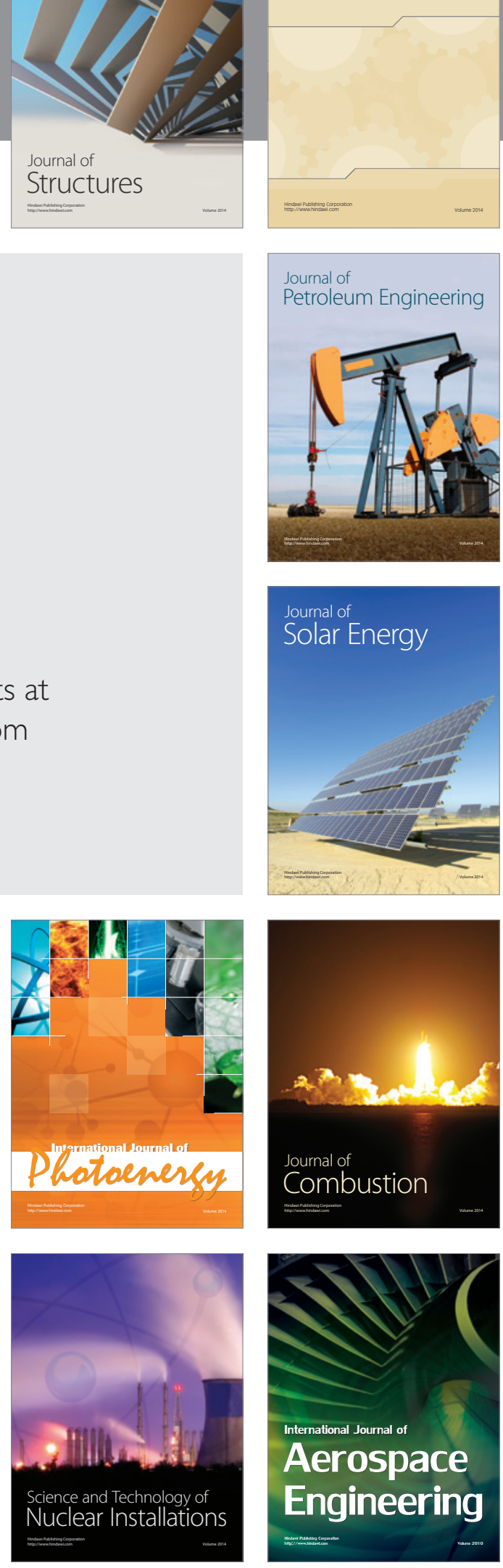